\title{
Reseñas de prensa: fuente para el estudio de la recepción de Cervantes en ediciones y traducciones británicas del siglo XVIII*
}

\author{
MóniCA Amenedo Costa**
}

\begin{abstract}
Resumen
En el siglo XVIII, la prensa literaria inglesa ofrecía al lector valoraciones críticas sobre las novedades editoriales que salían al mercado. Esta labor periodística, que proporciona una visión sobre la recepción de obras y autores concretos, se ha empleado en este trabajo para estudiar la huella de Miguel de Cervantes en la tradición literaria inglesa en aquella centuria. Desde esta perspectiva, se ha llevado a cabo una recopilación de textos publicados en las revistas especializadas en la revisión de obras impresas The Monthly Review (17491845) y The Critical Review (1756-1817), poniendo el foco en los juicios de valor emitidos sobre las traducciones y ediciones de la obra cervantina. El propósito ha sido evaluar la recepción de estos trabajos, así como dar visibilidad al discurso que se articuló en torno a la figura de Cervantes y su producción literaria.
\end{abstract}

Palabras clave: revistas literarias; recepción; Cervantes; literatura inglesa; siglo XVIII.

Title: Book reviews: a new source for the study of the reception of Cervantes in eighteenth-century British editions and translations

\footnotetext{
Abstract

In the eighteenth century, the English literary press offered evaluative comments on newly published material. This journalistic activity gives a comprehensive view of the reception of specific works and authors, and has been employed in this study to examine

* Este trabajo forma parte del proyecto «Recepción e interpretación del Quijote (1605-1830). Traducciones, opiniones, recreaciones» (Ministerio de Economía e Innovación, ref.: FFI2014-56414-P).

** Universidad Complutense de Madrid. mamenedo@ucm.es / ORCID iD: https://orcid.org/00000001-6727-7512.
} 
Miguel de Cervantes's influence upon English literature at that time. From this perspective, this work concentrates on the analysis of book notices published in the literary journals The Monthly Review (1749-1845) and The Critical Review (1756-1817). Particular emphasis has been placed on studying the review comments that document the translations and editions of Cervantes's works. The aim has been to assess their reception as well as to reconstruct the critical discourse that was produced about Cervantes and his literary production.

Keywords: Literary journals; Reception; Cervantes; English literature; Eighteenth century.

\section{Cómo citar este artículo / Citation}

Amenedo Costa, Mónica (2019). «Reseñas de prensa: fuente para el estudio de la recepción de Cervantes en ediciones y traducciones británicas del siglo XVIII», Anales Cervantinos. 51, pp. 313-332, https://doi.org/10.3989/anacervantinos.2019.014.

\section{ReVistas Literarias INGLESAS: THE MONTHLY REVIEW Y THE CRITICAL REVIEW}

En el siglo XVIII se inicia un nuevo ciclo en la historia del periodismo británico, favorecido por la expiración de la Licensing Act en 1695, que influyó notablemente en la edición de nuevas publicaciones periódicas. Algunas de ellas se especializaron en diversas ramas del saber, como fue el caso de las revistas de crítica literaria The Monthly Review y The Critical Review. Su aparición, a mediados de siglo, contribuyó a la difusión de juicios de valor de las novedades bibliográficas que salían al mercado. Tanto The Monthly Review, establecida en 1749 por el librero Ralph Griffiths (c. 1720-1803), como The Critical Review, fundada en 1756 por Archibald Hamilton (1719-1793) y Tobias Smollett (1721-1771), contaron con destacados colaboradores. Entre ellos cabe citar a los escritores Samuel Johnson (1709-1784), David Hume (1711-1776), John Hawkesworth (c. 1715-1773), James Grainger (1721-1766), Oliver Goldsmith (1728-1774), John Langhorne (1735-1779) y Richard Brinsley Sheridan (1751-1816) (Graham 1930: 210, 213; Roper 1978: 22).

Desde sus orígenes, ambas cabeceras se propusieron ofrecer información de todas las obras impresas que salían a la luz sin distinción de materia o prestigio literario: «We propose, for the future, to register all the new Things, in general, without exception to any, on account of their lowness of Rank, or Price» (The Monthly Review 1, julio 1749: 238). Este compromiso llevó a los evaluadores a leer una gran cantidad de libros de escasa calidad, tarea por la que mostraron una enorme insatisfacción (Forster 1990: 5), pero posibilitó la apertura del horizonte de la crítica literaria, que también se había planteado incorporar en las reseñas juicios de valor, resúmenes y citas: 
The judicious reader will perceive that their aim has been to exhibit a succinct plan of every performance; to point out the most striking beauties and glaring defects; to illustrate their remarks with proper quotations; and to convey these remarks in such a manner, as might best conduce to the entertainment of the public (The Critical Review 1, 1756).

Todo ello suponía un cambio significativo con respecto a lo que se había venido ofreciendo previamente en revistas de similar naturaleza como Journal des Sçavans (1665-1792, 1797, 1816-actualidad), Memoirs of Literature (1710-1714), New Memoirs of Literature (1725-1727), The Present State of the Republic of Letters (1728-1736) o The Literary Journal (1730-1731) y contribuyó a que las nuevas cabeceras de prensa literarias consiguieran conectar con un amplio espectro de lectores del que las publicaciones anteriores habían carecido (Roper 1978: 20).

The Monthly Review y The Critical Review establecieron un punto de partida hacia un nuevo modelo de interpretación de los textos impresos, acercando el entendimiento literario al público lector y propiciando la adopción de una actitud crítica activa frente a los mismos. No en vano, el contenido informativo de estos medios de comunicación, que han conformado un acervo de conocimiento valioso para determinar con detalle la respuesta de la crítica ante las obras que se produjeron dentro de aquel contexto sociocultural, resulta de relevancia para avanzar en el estudio de la recepción de Miguel de Cervantes en la literatura inglesa del siglo XVIII ${ }^{1}$. Por ello, en este trabajo se ha contemplado la recopilación de documentos hemerográficos y el análisis e interpretación de sus datos en lo relativo a las traducciones y ediciones de la obra cervantina desde su creación hasta finales de la centuria ${ }^{2}$. Como tal, viene a completar los estudios que se publicaron, siguiendo este mismo enfo-

1. Esta metodología brinda la posibilidad de realizar nuevas investigaciones que permitan una valoración más profunda sobre la contribución de las publicaciones periódicas británicas al cervantismo. El éxito de The Monthly Review pronto llevó a que otras cabeceras de prensa literaria emergieran en el panorama cultural tales como The Literary Magazine (1756-1758), The Edinburgh Magazine and Review (1773-1776), The English Review (1783-1796) o The Analytical Review (1788-1799). Esta línea de investigación no solo sería pertinente para considerar las reseñas producidas por estas fuentes de prensa sino también para vincular su análisis hemerográfico con otras tradiciones críticas europeas. Todo ello le otorgaría al lector una visión conjunta sobre la relación de las publicaciones periódicas con la recepción europea de Cervantes o de otros autores.

2. A continuación se presentan las referencias documentales de los artículos analizados:

Festivous Notes on the History of the Renowned Don Quixote (The Monthly Review 39, julio 1768: 67-68; The Critical Review 26, septiembre 1768: 203-206).

The Life of Cervantes (The Monthly Review 74, abril 1786: 311-312; The Critical Review 60, agosto 1785: 94-96).

Tolondron (The Critical Review 61, junio 1786: 441-443).

The History of the renowned Don Quixote (The Monthly Review 13, septiembre 1755: 196-202).

A Dialogue between Scipio and Berganza, two Dogs belonging to the City of Toledo, [...]. To which is annexed the comical History of Rincon and Cortado, both written by the Celebrated Author of Don Quixote, and now first translated from the Spanish original (The Monthly Review 36, mayo 1767: 399).

A Letter to the Rev. Dr. Percy concerning a new and classical Edition of Historia del valeroso Cavallero DON QUIXOTE DE LA MANCHA, [...] (The Monthly Review 57, julio 1777: 80). 
que, sobre la impronta cervantina en la tradición literaria británica de aquel periodo (Amenedo 2017, 2019). En su conjunto, enmarcan la recepción de Cervantes en la novela, dramaturgia, composiciones musicales, traducciones y ediciones británicas.

\section{RECEPCIÓN CRÍTICA DE EDICIONES Y TRADUCCIONES CERVANTINAS}

La evaluación de estas fuentes hemerográficas evidencia que en ellas no solo se dedican palabras de elogio a Cervantes, a quien se identifica como un célebre escritor (The Monthly Review 27, julio 1762: 51; The Critical Review 14, julio 1763: 18; The Monthly Review, serie 2.18, diciembre 1795: 386), sino también palabras de lamento y reproche a su país por haberle conducido a vivir en la pobreza y no haberle honrado en vida ${ }^{3}$ :

Few authors have received their laurels in their life-time: that compliment has generally been reserved for their statues. Possibly the world may have judged it preposterous to honour any one with an apotheosis before his death. Homer was once a ballad-singer, is now a bard: Skakespeare lived a precarious hireling: Milton's divine poem lay long neglected, and was sold for a song: Otway lived and died in a corner: Cervantes passed his days in obscurity and poverty, a reproach to Spain (The Monthly Review 42, April 1770: 296).

Las reseñas de las traducciones y ediciones del Quijote publicadas en ambas revistas a lo largo de la segunda mitad del siglo XVIII ponen de manifiesto la huella de Cervantes en la tradición literaria inglesa ${ }^{4}$. Tal y como ha explicado el hispanista James Fitzmaurice-Kelly:

England was the first foreign country to mention Don Quixote, the first to translate the book, the first country in Europe to present it decently garbed in its native tongue, the first to indicate the birthplace of the author, the first to provide a biography of him, the first to publish a commentary on Don Quixote, and the first to issue a critical edition of the text (1905: 19).

Historia del famoso Cavallero Don Quixote de la Mancha. Por Miguel de Cervantes Saavedra. Con Anotaciones, Indices, y varias Lecciones: por el Reverendo D. Juan Bowle (The Monthly Review 68, mayo 1783: 421-424).

3. En el año 1780, «[c]omo desquite por la tardanza y el improperio, la Real Academia Española de la Lengua le rinde el tributo que se merece con la publicación de una lujosa edición del Quijote, [...]» (Rey y Muñoz 2006: 54-55).

4. Entre los autores que han estudiado las traducciones y ediciones del Quijote cabe citar a Fitzmaurice-Kelly (1905), Gerhard (1982), Cunchillos (1993; 1987), Eisenberg (2003), Garrido Ardila (2005; 2006), Carretero Muñoz (2005), Martínez Torrón (2005), Álvarez Calleja (2007), Álvarez Faedo (2007), Rutherford (2007), Valdés (2007), Hayes (2009), y Mayo y Garrido Ardila (2009). Luttikhuizen (1985) se ha centrado específicamente en las traducciones inglesas de las Novelas Ejemplares. 
Sin embargo, la trascendencia de Cervantes en las letras inglesas no se concentró exclusivamente en su obra maestra. Las valoraciones de las traducciones de El coloquio de los perros y Rinconete y Cortadillo, así como la de una biografía titulada The Life of Cervantes, acreditan que su influencia se proyectó hacia otras producciones literarias que también se acercaron al público inglés del siglo XVIII.

\subsection{Festivous Notes on the History of the Renowned Don Quixote}

La publicación de Festivous Notes on the History of the Renowned Don Quixote, en 1768, confirma que el Quijote seguía siendo una novela muy apreciada en Inglaterra por aquel entonces. Festivous Notes era una edición revisada de Pleasant Notes upon Don Quixot, que había salido al mercado a mediados del siglo anterior y que no solo era el primer comentario crítico del Quijote sino que además reflejaba «la percepción de la novela de Cervantes que en Inglaterra se tuvo inmediatamente después de su publicación en 1654» (Garrido 2009: 94). La reimpresión de Pleasant Notes se había editado en un inglés más claro, propio del siglo ilustrado (Colahan 2013: 162-163), con correcciones, modificaciones y adiciones, así como con un extenso índice: «Revised, with Corrections, Alterations, and Additions; and adapted to the Modern Translations of that celebrated work. To which is added, a Copious Index» (The Critical Review 26, septiembre 1768: 203) $)^{5}$.

$\mathrm{El}$ análisis ofrecido por la prensa literaria reduce el mérito de este trabajo porque en él se aprecia un excesivo derroche de verbosidad así como unos textos y unas notas que no habían contribuido lo más mínimo a mejorar el original (The Critical Review 26, septiembre 1768: 205). Todo lo contrario, se sostiene que la omisión de las anotaciones habría contribuido a una mejor aceptación de la obra (The Monthly Review 39, julio 1768: 68). Ambas cabeceras convienen con la reflexión que el editor había trasladado a sus lectores acerca de su edición porque con ella no había intentado esclarecer la célebre historia de don Quijote sino únicamente aportar unos comentarios entretenidos e ingeniosos sobre diversos fragmentos e incidentes de la propia historia, ilustrados con relatos cómicos (The Critical Review 26, septiembre 1768: 205). Lo cierto es que The Monthly Review no solo no toma en consideración sus observaciones, que describe como «trivial, bald, punning and pedantic» (39, julio 1768: 68), sino que tampoco valora sus historias intercaladas, que llevan a juzgar la nueva edición como un mero libro de broma. El objetivo del editor habría obtenido su aprobación si tanto él como el autor, Edmund Gayton, hubieran parodiado una obra ridículamente seria pero, por desgracia,

5. Véase Festivous Notes on the History and Adventures of the Renowned Don Quixote. First Published by Edmund Gayton, Esq.; In the Year 1654. Revised, with corrections, alterations, and additions; and adapted to the Modern Translations of that celebrated Work. To which is added a Copious Index, by the Editor (1768). 
se daba el caso de que el humor tan admirado en el Quijote hacía que su discurso buslesco y humorístico pareciera más bien todo un inconveniente (The Monthly Review 39, julio 1768: 68). Esta reprobación también es sustentada por The Critical Review, que caracteriza el humor de Gayton como muy próximo de caer en la obscenidad. La revista manifiesta su total oposición a la convicción del editor sobre el alto grado de originalidad del que estaban dotadas las bromas de la obra, aun a pesar de que, en ocasiones, reconociera que eran rudas e incluso algo indecentes, razón por la cual se había tomado la molestia, que esperaba que fuera apreciada por el público, de extraer cuidadosamente los elementos indeseados del texto, tal y como había realizado Heracles cuando se había encargado de limpiar los sucios establos del rey Augías:

Mr Gayton appears to have been a great punster, and to have been well
furnished with common-place stories. His jokes are sometimes low, but his
editor thinks that they bear strong marks of originality; and he confesses
that they are sometimes indelicate, not to say indecent, and hopes that the
reader will find he has carefully cleansed the Augaean stable (The Critical
Review 26, septiembre 1768: 205).

Con estas argumentaciones, la crítica inglesa reconoce el talento de Cervantes así como el humor debidamente admirado en el Quijote. No obstante, manifiesta su incomodidad ante las observaciones y comentarios presentes en la edición, que se consideran totalmente innecesarios para su buena acogida: «In brief, it happens in this, as in many other instances, that the text is more aceptable without the commentary than with it» (The Monthly Review 39, julio 1768: 68). Asimismo, cuestiona el tono cómico-burlesco de la obra de Gayton, que había sido producida en una centuria en la que solo se veían en el Quijote «el humor, la comedia baja y la farsa a costa del personaje quijotesco y su degradación burlesca» (Pardo 2007: 134).

Unos errores anacrónicos presentes en el texto también llevan a la prensa a adoptar una postura reticente con respecto a este trabajo. En este punto se cita, a modo de ejemplos, la sociedad científica Royal Society, porque en el año 1654 aún no se había creado, a Sally Salisbury (c. 1692-1724), una famosa prostituta de Londres del siglo XVIII, a Elizabeth Canning (1734-1773), una sirvienta que afirmó haber sido secuestrada y retenida contra su voluntad durante casi un mes en el año 1753, y al fantasma de Cock Lane, cuyas manifestaciones produjeron un tremendo impacto en Londres en 1762 (The Critical Review 26, septiembre 1768: 205-206). Ante el conjunto de estas discrepancias, la crítica no se abstiene a mostrar su desconcierto sobre esta publicación y reconoce no saber cómo interpretarla, aunque afirma haber encontrado en ella una amplia variedad de juegos de palabras, acertijos, comentarios jocosos y anécdotas que probablemente serían una garantía de entretenimiento para algunos lectores (The Critical Review 26, septiembre 1768: 206). A través de los comentarios que se leen en esta valoración, es posible constatar que la visión ilustrada cuestiona la perspectiva burlesca de esta obra 
que había sido producida por un editor que tampoco había tratado de iluminar las todavía partes oscuras del Quijote.

\subsection{Edición del Quijote de John Bowle}

Un nuevo testimonio de la destacada recepción del Quijote en Inglaterra lo constituye la edición comentada del reverendo John Bowle (1725-1788), que vio la luz en $1781^{6}$. El interés y conocimiento que Bowle tenía sobre la literatura española le llevaron a hacer esta edición «en castellano, porque consideraba que Cervantes y Shakespeare eran los dos referentes básicos de la literatura europea: [...]» (Rey y Muñoz 2006: 51). El propio Bowle se encargó de anunciar su trabajo en A Letter to the Reverend Dr. Percy concerning a New and Classical Edition of Historia del Valeroso Cavallero Don Quixote de la Mancha, impresa en Londres en 1777. La recensión de esta carta es empleada por la crítica para desearle éxito al editor en este valioso proyecto que había sido diseñado para intentar esclarecer los usos y costumbres de la época de Cervantes (The Monthly Review 57, julio 1777: 80). Unos años más tarde, Bowle sacaba a la luz el artículo titulado «The Life of Cervantes», en el que daba a conocer que ya tenía casi finalizada su edición del Quijote. Comenzaba este adelanto de la vida de Cervantes haciendo un claro reconocimiento al inmortal escritor y resaltando que el desconocimiento de sus orígenes durante tanto tiempo seguía representando un motivo de sorpresa dado que no solo había dado gloria a su país sino también al conjunto de la humanidad:

It will doubtless appear matter of surprise, that the family, birth, and place of nativity, of a man, who was so great an ornament to his country and mankind as Miguel de Cervantes Saavedra, should for such a long period of time have continued unknown (The Gentleman's Magazine 51, 1781: 22).

La biografía La vida de Miguel de Cervantes Saavedra (1738), de Gregorio Mayans y Siscar, promovida por lord Carteret, no recibía su reconocimiento porque no solo no permitía remontarse a la etapa temprana de la vida del autor sino porque proporcionaba datos erróneos sobre su lugar de origen. Por

6. Entre las ediciones del Quijote que aparecieron en el transcurso del siglo XVIII cabe mencionar la publicada en Londres por Jacob Tonson que abochornó a las reimpresiones que se habían llevado a cabo en España y en otros lugares (Fitzmaurice-Kelly 1905: 17). Esta edición apareció en Londres en 1738 y fue revisada por Pedro de Pineda. Martínez Mata la describe como «la primera monumental del Quijote por la elegancia de la tipografía, la calidad de sus grabados, etc. [...]» (2001: 1202). En ella se incluyó la primera biografía formal de Cervantes, Vida de Miguel de Cervantes Saavedra, escrita por el erudito y humanista valenciano, Gregorio Mayans y Siscar (1699-1781), por encargo del ex secretario de Estado británico, John Carteret, Lord Granville (1690-1763) (Fitzmaurice-Kelly 1905: 17; Martínez 2001: 1202). 
el contrario, opinaba que Noticias para la vida de Miguel de Cervantes (1778), que acababa de salir al mercado de la mano de Juan Antonio Pellicer y Saforcada, incluía datos biográficos de valor que no obvió reproducir en su artículo con el fin de ponerlos al alcance del público inglés (The Gentleman's Magazine 51, 1781: 23-24). Su lectura abría la posibilidad de adentrarse en la trayectoria vital de Cervantes. De ahí, tal y como relata Cuevas Cervera, que esta biografía documental supusiera «todo un hito en la historia del cervantismo» (2016: 182).

Una vez publicada la edición de Bowle, su elogio se deja patente desde el inicio del artículo de prensa ${ }^{7}$. El Quijote se describe como «the most exquisite and most inimitable of romances» (The Monthly Review 68, mayo 1783: 421) y a Bowle se le reconoce el gran esfuerzo realizado para explicar el contexto cervantino a través de la descripción del significado de numerosos modismos, términos y expresiones. La edición era enormemente apreciada por la voluntad del editor de esclarecer los pasajes que el tiempo había oscurecido, especialmente aquellos que aludían a lugares, personas y textos impresos. Y, aunque no cabía esperar una explicación perfecta de todos ellos porque algunos ya habían caído en el olvido, se resalta el valor de las explicaciones aportadas, para cuya comprensión no habría sido necesario un diccionario en caso de haber sido escritas en inglés en lugar de en español. La crítica se muestra totalmente agradecida por poder contar con los elementos necesarios para interpretar y formar un juicio crítico sobre un tema concreto y poder rescatar, así, su auténtico significado (The Monthly Review 68, mayo 1783: 421). Por todo ello, las anotaciones contenidas en esta edición se califican como un aporte de gran valor para dar testimonio de las bellezas del Quijote.

La inclusión de la nota sobre la historia de Ignacio de Loyola, narrada por el escritor Pedro de Ribadeneyra (1526-1611), había sido clave para conocer la decisión del religioso de armarse caballero de la Virgen María una noche que había pasado ante su imagen, al tiempo que había ayudado a vislumbrar una interesante asociación entre don Quijote e Ignacio de Loyola ${ }^{8}$. Este tipo de notas que, a decir de la crítica, eran ilustrativas de la singularidad de la obra de Cervantes, llevan implícito el lamento de que el laborioso editor no hubiera sido capaz de recopilar más datos con los que favorecer el conocimiento de curiosas expresiones y dichos populares como "[p]onerme en la espina de Santa Lucía» (The Monthly Review 68, mayo 1783: 422). La falta de información sobre esta frase empleada por Sancho había impedido comprender por qué se hacía referencia en ella a la espina de dicha santa. Pese a estas limitaciones, el artículo de prensa felicita a Bowle por su meritorio trabajo y ofrece nuevas muestras de su extraordinaria valía. De manera particular alude a unos versos del poeta Luis Barahona de Soto (1548-1595)

7. Al final del volumen 67, publicado en 1782, The Monthly Review incluye una nota en la que da a conocer que se estaba llevando a cabo el análisis de este trabajo.

8. La lectura de la Vida del Padre Ignacio de Loyola, de Ribadeneyra, había permitido «a Bowle retratar detalladamente los parecidos del Santo con don Quijote» (Davison 2012: 57). 
porque habían sido esenciales para la resolución del enigma que se encerraba detrás de las cuatro eses que había de tener un buen amante (The Monthly Review 68, mayo 1783: 422):

De quatro esses dizen que esta armado

Sabio, solo, solicito, y secreto:

Sabio, en servir, y nunca descuydado,

Solo, en amar, y a otra alma no sujeto,

Solicito, en buscar sus desenganos:

Secreto, en sus fabores, y en sus danos

La reproducción de estos versos había sido decisiva también para lograr una mejor comprensión del autor porque en ellos se revelaba el mal gusto de los escritores de su época que se señala como la principal pretensión de su trabajo:

This citation, though it may give little pleasure to the improved age in which we live, is so far necessary to the complete understanding of our Author, that it serves to give a fresh instance of the false taste of the writers of his time -which was the principal design of his work (The Monthly Review 68, mayo 1783: 422).

El reconocimiento de Bowle por parte de la crítica llega gracias a su esfuerzo para incorporar didácticos comentarios en su edición, tal y como se advierte en aquellos que proporcionaban explicaciones sobre las cuatro primeras órdenes menores a las que accedían los eclesiásticos, ostiario, lector, exorcista y acólito, o sobre la figura de Don Manuel de León. La comparación entre este caballero y don Quijote había permitido acceder a la increíble historia relatada por Alonso Lope de Haro en la que se narraba cómo Don Manuel se había metido con extraordinaria valentía en una jaula de leones para recuperar el guante que allí se le había caído a una de las damas de la corte de los Reyes Católicos. A partir de aquel momento, se le había bautizado con el nombre de Don Manuel de León (The Monthly Review 68, mayo 1783: 422). La labor del editor, prosigue la crítica en su exposición, había contribuido a conocer por qué la infanta Doña Urraca vagaba por el mundo, tal y como se interpretaba en el romance de Pedro de Flores, recogido en la tercera parte del Romancero General en que se contienen todos los Romances que andan impresos (1604: 83-84), del que se citan los siguientes versos (The Monthly Review 68, mayo 1783: 423):

Acabando el Rey Fernando,

De distribuyr sus tierras,

Por la sala triste,

De negro luto cubierta,

La olvidada infanta Urraca,

Delante su padre el Rey,

De hinojos ante la cama, 
Las manos le pide y besa.

En traje de peregrina,

Partire, mas faced cuenta,

Sin varon, y sin facienda.

Si tierras no me dexays,

Yo me yre a las agenas

Como ilustran estos ejemplos, se genera un discurso periodístico que resalta los elementos más destacables y valiosos de la edición. El estudio crítico aporta, además, un componente descriptivo que revela el contenido de los volúmenes que la integran. A través de él se conoce que los cuatro primeros reunían la historia original de Don Quijote mientras que el quinto recogía las notas. El sexto incluía un extenso índice, que gana el aplauso del evaluador que se considera un gran admirador de los índices, especialmente en trabajos de dimensiones considerables, cuya omisión les haría perder buena parte de su mérito (The Monthly Review 68, mayo 1783: 423-424). La crítica reconoce que esta edición no estaba exenta de incorrecciones gramaticales ni ortográficas, pero subraya su alto valor literario así como la inestimable aportación del editor al mundo de las letras, una apreciación que sigue siendo compartida en la actualidad. Rey Hazas y Muñoz Sánchez opinan que sus errores no llegan a empañar «su extraordinario trabajo filológico [...]» (2006: 52), al igual que Frans De Bruyn, que afirma que sus anotaciones se reconocen como el fundamento de las sucesivas composiciones editoriales del Quijote (2009: 43).

La edición del reverendo inglés motivó la publicación de Tolondron. Speeches to John Bowle about his Edition of Don Quixote (1786). Su autor, el escritor italiano Joseph Baretti ${ }^{9}$, ataca en ella a Bowle, a quien describe como un tolondrón. El sentido literal de este término era el de roncha o chichón provocado por un golpe, pero se empleaba de manera figurada para hacer alusión a una persona estúpida y charlatana. Explica el crítico de la época que en la primera acepción no se evidenciaba fácilmente la segunda a no ser que guardara cierta relación con el dicho «that the fool shall be beaten with many stripes ${ }^{10}{ }^{10}$, una deducción que pensaba podía ser cierta, dado el fuerte sentimiento religioso de los españoles:

The word literally means a wheal on the skin, raised by a stripe or a blow; but its common metaphorical interpretation is a stupid ignorant pretender

9. En 1751 Baretti (1719-1789) se trasladó a Londres. Allí residió hasta 1760 y entabló relación con figuras del mundo intelectual como el escritor Samuel Johnson. Entre 1760 y 1762 viajó por la península ibérica y Francia, tal y como atestigua su obra A Journey from London to Genoa, through England, Portugal, Spain, and France (1770). En 1778, publica en Londres, a donde había regresado en 1776, su diccionario bilingüe A Dictionary, Spanish and English, and English and Spanish que tuvo un gran éxito y «presenta como 'segunda edición', considerando pues como primera A Dictionary, Spanish and English, and English and Spanish de Joseph Giral Delpino» (Mühlschlegel 2011: 100).

10. Este verso bíblico establece que el siervo que no obra de acuerdo a la voluntad de su señor, aun conociéndola, recibirá muchos azotes. 
to knowledge: we cannot trace the first meaning down to the second, unless it be 'that the fool shall be beaten with many stripes;' and as the Spaniards are a very religious nation, perhaps we may be right (The Critical Review 61, junio 1786: 441-443).

En la valoración de este trabajo se da a conocer que Bowle, a quien se reconoce como el editor de una magnífica edición del Quijote, se había cogido un enfado desproporcionado a raíz de la ayuda que le había ofrecido Baretti cuando todavía eran amigos, o al menos no combatientes, tras detectar unos errores de acentuación en una impresión de prueba. Dado que los errores oscurecían el sentido del mensaje, llegando, incluso a veces, a alterarlo, Baretti decidió corregirlos en notas en los márgenes de un ejemplar que había caído en sus manos, a pesar de que Bowle había declinado su ayuda.

Aunque la crítica reproduce la polémica, en este comentario parece insinuar que Bowle no debería haberse sentido tan humillado por la intromisión de Baretti, hasta el punto de sentirse impulsado a involucrarse en la producción de Remarks on the Extraordinary Conduct of the Knight of the Ten Stars and his Italian Squire (1785) y «Letter to a Doctor of Divinity» (The Critical Review 61, junio 1786: 442). La manera tan severa en la que atacó a Baretti en estas publicaciones y en algunas cartas que vieron la luz en la revista The Gentleman's Magazine (1731-1922), llevaron al escritor italiano a elaborar Tolondron, una obra muy crítica con Bowle, con sus interpretaciones erróneas y absurdas de muchas palabras, así como con su desconocimiento de la lengua española, especialmente con el método aleatorio y frecuentemente inapropiado del que hacía uso para la colocación de los acentos (The Critical Review 61, junio 1786: 441-442).

El crítico argumenta que carecía de la información necesaria para poder formular una opinión sobre este asunto. No obstante, cuestiona el modo tan poco juicioso de actuar de Baretti, dejando sentir, de este modo, su participación en la discusión. Sabía que Baretti había mostrado su enfado, y probablemente con razón, pero opinaba que había perseguido sus triunfos con poca piedad, saliendo victorioso en algunos casos. Con respecto al editor, indica que todavía podría alegar en su defensa, si realmente era el autor de las publicaciones mencionadas, a pesar de que no se había acogido siempre a un uso idiomático de la lengua, no había explicado algunas palabras de manera muy inteligible, ni tampoco había cuidado la extensión del texto. Sobre este último aspecto, establece que había sido más voluminoso de lo que cabría esperar, al igual que sucedía con Tolondron, una obra de la que tampoco aprueba la manera inconexa y poco sólida en la que estaba escrita (The Critical Review 61, junio 1786: 442). A pesar de estos errores lingüísticos, se puede decir que la edición de Bowle recibió una buena acogida por la crítica, a quien no le faltaron argumentos para mostrar la riqueza de sus notas y referencias ni tampoco para reconocer el esfuerzo del editor. Sus palabras de elogio, a la luz de las destacadas aportaciones que los evaluadores consideraban imprescindibles para comprender pasajes ignorados, conocidos únicamen- 
te por quienes habían sido sus lectores originales, reconocen la trascendencia y el impacto de esta edición en la historia del texto cervantino. En aquel momento, y gracias a la labor de Bowle, aquellas palabras y frases olvidadas eran también accesibles para los lectores ingleses que, con ellas, podían adentrarse en la época del Siglo de Oro español.

\subsection{Traducción del Quijote de Tobias Smollett}

Además de la edición de Bowle, la impronta cervantina en la literatura inglesa ha dejado su huella en la reseña de la traducción del Quijote de Tobias Smollett, publicada en 1755, que constituye otra clara muestra de que Cervantes seguía siendo interpretado en Gran Bretaña en aquella época. El juicio de valor de esta traducción se publica bajo la entrada The History of the renowned Don Quixote. Translated from the Spanish of Miguel de Cervantes Saavedra. To which is prefixed, some account of the Author's life. By T. Smollet, M. D. Illustrated with 28 new copperplates, designed by Hayman, and engraved by the best artists. In two volumes (The Monthly Review 13, septiembre 1755: 196) ${ }^{11}$. Tal y como se da a conocer en el título, en ella se incluyen datos biográficos de Cervantes que Smollett había querido proporcionar con el fin de ensalzar sus «cualidades humanas y literarias» (Garrido 2006: 40). La traducción se presentaba en dos volúmenes. Iba ilustrada con veintiocho estampas diseñadas por Francis Hayman (1708-1776) y grabadas por los mejores artistas. Su excelencia con respecto a los grabados y a las características del papel le imprimían, a juicio del crítico, un carácter elegante y refinado (The Monthly Review 13, septiembre 1755: 196).

Smollett había emprendido este proyecto años después de que otros autores hubieran dedicado sus esfuerzos a traducir el Quijote. Por este motivo, su traducción se compara con la de Charles Jervas (o Jarvis) (c. 1675-1739), que había visto la luz en 1742, y con la de Peter Anthony Motteux (1663-1718), publicada en 1700 y «reeditada en numerosas ocasiones a lo largo del XVIII y del XIX» (Martínez 2001: 1205). La crítica aprecia diferencias entre la versión de Jarvis y la de Smollett, y comparte con los lectores un fragmento extraído de ambas para que pudieran juzgar por sí mismos, en caso de que estuvieran en posesión de la versión original y sintieran la curiosidad de compararlas. El pasaje seleccionado narra la estancia de don Quijote y Sancho en casa de los duques, y recoge la anécdota contada por Sancho en aquella ocasión (The Monthly Review 13, septiembre 1755: 198-202). Las traducciones de traducciones publicadas por Motteux, entre otros autores, no merecían ninguna otra mención excepto la de expresar el asombro de que, bajo el velo

11. En 1612, Thomas Shelton había publicado una traducción de la primera parte del Quijote, años antes de que Cervantes sacara a la luz la segunda, en 1615. Fue la primera traducción de la obra al inglés (Fitzmaurice-Kelly 1905: 17). 
burlesco y el disfraz ridículo en los que envolvieron al autor, no fueran capaces de alejarle de la excelencia que lo caracterizaba. Con esta argumentación, la crítica se muestra abiertamente insatisfecha con la versión del escritor anglo-francés, que se considera estar lejos de ser la mejor traducción inglesa del Quijote (The Monthly Review 13, septiembre 1755: 197) ${ }^{12}$. Por el contrario, reconoce el mérito en la de Smollett, que había transformado hacia lo humorístico y lo satírico esta perspectiva cómica y burlesca (The Monthly Review 13, septiembre 1755: 196). Sostiene que en su publicación había conseguido recuperar la sátira y la formalidad de muchas referencias que parecían completamente perdidas como consecuencia inexorable del paso del tiempo y de los cambios ocurridos en las costumbres. Asimismo, había cumplido la tarea de conservar el espíritu y las ideas del original sin adherirse servilmente a la expresión literal (The Monthly Review 13, septiembre 1755: 196-197). Smollett no solo había llevado a cabo su cometido con suma prudencia y cuidado, sino que además no había mermado lo más mínimo la transmisión de la formalidad de los modismos, unas expresiones características de los españoles y fundamentales para entender la esencia de la obra. Por todo ello, su versión era la que más se aproximaba al «great original», palabras con las que la novela de Cervantes suma un nuevo reconocimiento en la prensa literaria inglesa del siglo XVIII (The Monthly Review 13, septiembre 1755: 197). Estas valoraciones ponen de manifiesto que la traducción fue elogiada por la crítica, que destacó su importancia para comprender el texto y valoró su impacto a la hora de ilustrar el contexto cervantino.

El lado oscuro de su faceta como traductor se hacía visible en las limitaciones a las que probablemente había estado expuesto porque el Quijote era, quizás, el libro más difícil de traducir y, por esta sencilla razón, el más difícil de entender también. De ahí que muy pocas personas, entre quienes se incluía a los españoles de aquella época, fueran ya capaces de apreciar toda su belleza o detectar, incluso, las sombras ocasionadas por el transcurso del tiempo (The Monthly Review 13, septiembre 1755: 197). Ante esta situación, la pregunta que cabía hacerse era ¿cómo podía esperarse que los ingleses se encontraran entre los grandes maestros de Cervantes? Cabría esperar que leyeran su obra con gran deleite en versión original, pero trasladar a otro idioma su espíritu, su excelente humor y la belleza de sus numerosas alusiones era ya una tarea que ni siquiera un genio de la talla del insigne autor podría realizar en un marco temporal y espacial tan remoto. Para ello sería preciso tener el mismo grado de conocimiento del país y de la época en la que había sido producida. Lamentablemente, este objetivo se percibe de antemano como inalcanzable y lleva a la crítica a mostrar su extrañeza ante la posibilidad de que pudiera salir al mercado una versión mejor que la de Smollett en un corto espacio de tiempo (The Monthly Review 13, septiembre 1755: 197). La omisión de un índice, que la versión de Jarvis sí había proporcionado, susten-

12. El excelente prólogo de la versión de Motteux, escrito por Lockhart en 1822, y no sus méritos, favoreció la realización de las reimpresiones de esta obra (Fitmaurice-Kelly 1905: 17). 
ta una apreciación desfavorable sobre la traducción de Smollett porque podía dificultar a los lectores el acceso a determinadas partes de la misma. Esta apreciación estaba respaldada por el hecho de que los índices eran elementos de gran utilidad de los que debía estar dotado cualquier libro de prestigio, aunque su inclusión pudiera fácilmente pasársele por alto a cualquier escritor de talento e imaginación. Por este motivo, el crítico deseaba que esta opinión no fuera entendida como una reprobación (The Monthly Review 13, septiembre 1755: 202), especialmente porque, tal y como había apuntado anteriormente, valoraba el mérito de esta obra así como la nueva significación otorgada al aspecto humorístico del Quijote, que se alejaba de la visión burlesca propia del Siglo de Oro.

\subsection{Traducción de El coloquio de los perros y Rinconete $\mathrm{y}$ Cortadillo}

El análisis de los textos recopilados de la prensa inglesa pone de manifiesto que el Quijote no fue la única obra de Cervantes que despertó el interés de autores y traductores en la Inglaterra del siglo XVIII. Esta afirmación se evidencia en la valoración de la traducción al inglés de El coloquio de los perros, que incorpora también la de Rinconete y Cortadillo. The Monthly Review anunciaba este trabajo en mayo de 1767 bajo la entrada titulada $A$ Dialogue between Scipio and Berganza, two Dogs belonging to the City of Toledo, giving an Account of their Lives and Adventures, with their Reflections on the Lives, Humours and Employments of the Masters they lived with. To which is annexed the comical History of Rincon and Cortado, both written by the Celebrated Author of Don Quixote, and now first translated from the Spanish Original (36, mayo 1767: 399). En la parte valorativa del artículo se reconocen ciertos toques del característico humor de Cervantes, a quien se define como un autor inimitable, a pesar de que estas producciones se situaban entre sus publicaciones menos afortunadas:

\footnotetext{
The inimitable Cervantes, like many other writers in the first Rank of genius, over-wrote himself, and through haste and necessity put a force upon those talents which are always best left to their natural exertion. These Dialogues, and the Comical History annexed to them, must be ranked among the number of his less fortunate publications; notwithstanding they are here and there distinguished by strokes of that humour which was so peculiarly his own (The Monthly Review 36, mayo 1767: 399).
}

Por este motivo, esta traducción no recibe mucha cobertura mediática y a este comentario inicial se añade únicamente un elemento descriptivo en el que, por un lado, se retrata a los perros Cipión y Berganza como críticos, moralistas y filósofos, así como autores de gran cantidad de comentarios agudos sobre la vida y las maneras de los hombres, y, por otro, se presenta a 
Rincón y Cortado como un carterista y un jugador, respectivamente. Ambos pícaros se integran en una sociedad de ladrones cuya economía política, leyes, máximas y religión se describen en tono humorístico y divertido (The Monthly Review 36, mayo 1767: 399).

\subsection{Traducción de Wallbeck de la Vie de Cervantes}

Años más tarde, ambas cabeceras de prensa registran la reseña de una traducción al inglés de una biografía de Cervantes, titulada The Life of Cervantes: Together with Remarks on his Writings, by Mr. de Florian. Translated from the French by William Wallbeck, que viene a formar parte de los estudios ingleses sobre aspectos biográficos y literarios del inmortal autor (The Critical Review 60, agosto 1785: 94-96; The Monthly Review 74, abril 1786: 311-312). La labor literaria de Jean-Pierre Claris de Florian, autor de la Vie de Cervantes [The Life of Cervantes], llega a la prensa respaldada por The Critical Review que emplea las palabras de William Wallbeck, su traductor, para destacar su talento como traductor, así como sus dotes de escritor y de crítico, unas palabras que le servían también para describir con ellas la obra y labor realizada por Wallbeck:

Mr. Florian, we now use Mr. Wallbeck's words, will 'be found to have executed his task as translator very ably. And I think, when you have perused The Life of Cervantes and the remarks upon his writings, you will agree with me that the Frenchman has evinced no less good sense, than liberality and candour; and, if he is not quite a Rousseau or D'Alembert, he is a good writer, and no despicable critic'.

We have transcribed these words because they are well fitted to characterize, this 'shadow of a shade', the translation from Florian. If we change the name, the fable will suit Mr Wallbeck and his work (60, agosto 1785: 94-95).

The Monthly Review no le concede una gran importancia a esta publicación, aunque informa que contenía datos no muy conocidos sobre la vida de Cervantes, así como algunas observaciones de su obra que no defraudarían a sus admiradores. El crítico deja patente que no era posible percibir las bellezas del Quijote sin sentir un profundo respeto y devoción por su autor. Por este motivo, se muestra interesado en adquirir cualquier tipo de información que tuviera que ver con la fortuna o el infortunio de un genio tan extraordinario como Cervantes. Estas impresiones le sirven para realzar su grandeza como escritor y para avalar el reconocimiento que la crítica literaria inglesa seguía otorgándole a finales del siglo XVIII:

For our part, we feel ourselves interested in whatever related to the fortunes, and, alas! the misfortunes, of so great a genius, -so eminent, so various, so instructive, so entertaining a writer! (The Monthly Review 74, abril 1786: 312). 
En la valoración le presta atención a la publicación de Florian, Vie de Cervantes, que había sido incorporada al comienzo de la traducción de $L a$ Galatea $^{13}$, un trabajo que Cervantes había dejado inconcluso y que el propio Florian había completado añadiéndole el cuarto y último libro después de condensar los seis volúmenes originales en tres. Más allá de estos datos, poco más podía aportar sobre el grado en que el escritor francés había asumido su tarea porque no había tenido acceso a su publicación, aunque su traducción al inglés parecía indicar que su recepción estaba siendo buena (The Monthly Review 74, abril 1786: 312). Dos ediciones publicadas simultáneamente en Ginebra y Bruselas al año siguiente de su salida al mercado avalaban su éxito, así como una traducción al polaco cuatro años después (Sabik 1990: 311).

La crítica reflexiona también en torno a Bernardo, otra de las obras inconclusas de Cervantes, y traslada al público inglés que Wallbeck había afirmado desconocer a qué se refería el autor del Quijote en su dedicatoria al Conde de Lemos cuando hacía alusión al «The Great Bernard» ${ }^{14}$. Sospechaba que podría tratarse del monte del Gran San Bernardo, entre Suiza e Italia, pero no estaba seguro de ello. A propósito de esta cuestión, trasladaba su interés y agradecimiento a cualquier persona que pudiera corregir esta apreciación, en caso de no estar en lo cierto, a través de un medio de comunicación serio y riguroso, como podía ser Gentleman's Magazine. El crítico se toma la molestia de indagar sobre esta reflexión del traductor y es capaz de averiguar que entre las obras que Cervantes no había llegado a concluir se encontraba Bernardo. Lamentablemente, no había podido recopilar la más mínima información sobre ella ni tampoco se le ocurría la manera de obtenerla y deduce que, fuera lo que fuera este trabajo, probablemente se hubiera perdido (The Critical Review 60, agosto 1785: 95).

Cervantes era reconocido como un escritor satírico y novelista, pero no se podía decir lo mismo sobre su faceta como dramaturgo. La constatación de esta apreciación se acerca a los lectores a través de una cita extraída del trabajo reseñado en la que se presentaban sus piezas teatrales como carentes de toda verosimilitud, a pesar de sus frecuentes dosis de ingenio. El argumento de The Fortunate Lecher [El rufián dichoso] corroboraba esta afirmación. A través de él se conocía que el primer acto de esta comedia discurría en Sevilla, donde el héroe era el mayor rufián de la ciudad, y que en el segundo se encontraba en México, donde la espiritualidad se abría paso tras este ambiente de pecado. Allí, convertido en el padre Cruz, había conseguido convencer a una mujer de vida disipada mediante un trato para que confesara sus pecados a la hora de la muerte y que los ángeles llevaran su

13. La obra de Florian, publicada en París en 1783, llevaba por título Galatée, Roman Pastoral; Imité de Cervantes, par M. de Florian.

14. En esta dedicatoria, Cervantes lamentaba no poder finalizar tres de sus obras inconclusas, Semanas del Jardín, Bernardo y La Galatea, que habría tenido el deseo de dedicar al Conde de Lemos (Claris de Florian 1785: 36) 
alma. El trato implicaba cambiar sus méritos por los pecados que ella había cometido. Por ello, cuando el padre debe atender las reclamaciones del demonio, descubre, con asombro, que se encontraba totalmente afectado de lepra. Finalmente fallecía en el tercer acto, en el que hacía milagros. Tras este breve resumen de El rufián dichoso, la reseña inserta la opinión que Florian había emitido sobre esta obra, que se resume con las siguientes palabras: "Such is the plot of a play written by the author of 'Don Quixote:' and perhaps the best play he ever wrote» (The Critical Review 60, agosto 1785: 96). Esta valoración del escritor francés iba acompañada de una nota del traductor que el crítico había seleccionado con la intención de ofrecer en su análisis una muestra de las mismas, así como de compartir con el público su parecer sobre esta comedia. En la nota se apelaba a la excentricidad de un genio como Cervantes, autor de una obra tan magnífica como el Quijote, para justificar la producción de una comedia tan abominable en la que se había desviado de toda forma de belleza y orden. Wallbeck explicaba que, de no haber sido publicada por Cervantes, el único atisbo de luz que le hubiera quedado para poder determinar que era él quien estaba detrás de su autoría habría provenido del atrevimiento con el que había descargado su vena satírica contra el clero todopoderoso. Argumentaba que este propósito no lo había llevado a cabo de manera directa en absoluto ni tampoco inhábil, tal y como parecía indicar la descripción proporcionada por Florian, sino todo lo contrario. Se había representado haciendo uso de la ironía y de la sátira encubierta. De otro modo, habría sido denunciado por la Santa Inquisición. El traductor inglés creía que en aquella época la ignorancia y la estupidez debían de ser enormes para no haber detectado la parodia en esta obra de Cervantes.

En la nota, Wallbeck también expresaba su deseo de que la palabra cruz se hubiera escogido con buena y seria intención para darle nombre a un personaje tan absurdo como el sacerdote, pues no era capaz de salir de su asombro al ver que dicho término, con el que se describía el preciado memorial de redención, había sido empleado para tal fin. Se preguntaba si alguien con un mínimo sentido religioso podría soportar tal visión que a él mismo le resultaba muy difícil de aprobar. A su entender, si algún escritor de obras de humor se había esforzado en inculcar la religión, ese era el del autor del Quijote, un libro en el que no había ningún capítulo en el que no abundaran los preceptos morales y religiosos, y cuyo personaje principal no olvidaba jamás a Dios, por muchas que fueran sus extravagancias. Por esta razón, absolvía a Cervantes de cualquier intención de blasfemia y recomendaba a los escritores que trataran de ser extremadamente cautelosos en el empleo de las palabras, dado que una aplicación incorrecta de las mismas podría poner en tela de juicio su sentido religioso incluso siglos después de su muerte (The Critical Review 60, agosto 1785: 96). Con esta exposición del traductor, la crítica pone fin a un artículo en el que se percibe una profunda admiración por el Quijote así como un claro reconocimiento a Cervantes, no tanto como dramaturgo sino como novelista y escritor satírico. 


\section{REFLEXIONES FINALES}

The Monthly Review y The Critical Review le aportaron un carácter moderno a la recepción de la producción escrita que les confirió un profundo significado y compromiso intelectual decisivo para el desarrollo de la crítica en aquella época. Obviamente, su mensaje de prensa contribuyó a la formación de una sensibilidad literaria en el público lector, marcando un punto de inflexión en la construcción de un pensamiento racionalista, de carácter analítico, propio de la Ilustración, que refleja el deseo de explicar y posicionar las obras en el ámbito de la literatura. Esta tarea se deja patente en las valoraciones de las ediciones y traducciones de las obras de Cervantes así como en sus comparaciones con grandes autores griegos e ingleses, como Homero, Shakespeare y Milton, haciendo sentir al lector que se encontraba ante un escritor consagrado dentro de las letras universales. La lectura de estos textos hemerográficos permite adentrarse en la visión crítica de la época relativa a la posición de Cervantes en el campo de la literatura y es una muestra de la apreciación y contribución de la crítica al conocimiento del autor en el siglo XVIII. Como destacados vehículos de transmisión literaria en la sociedad británica, ambas revistas realizaron una labor en la historia del cervantismo como materia de discusión filológica y literaria que muestra su relevancia como instrumentos de educación cultural y su trascendencia en el proceso de incorporación de Cervantes al canon de las letras inglesas.

En la producción de The Monthly Review y The Critical Review en torno a las traducciones y ediciones de la obra de Cervantes, se perpetúa su talento como escritor y se constata su influencia en la historia literaria inglesa. Estas novedades editoriales que proliferaban sobre su obra en el siglo XVIII corroboran la admiración que gozaba en Gran Bretaña. Tanto es así, que el interés por dar a conocer sus trabajos y pasajes de su vida seguía estando presente entre los círculos literarios de la época, tal y como se evidencia en las traducciones de El coloquio de los perros y Rinconete y Cortadillo y en The Life of Cervantes. Asimismo, estas publicaciones también avalan el reconocimiento de su producción literaria, especialmente del Quijote, una novela de la que los escritores británicos supieron aprovechar su potencial y versatilidad, y de la que ampliaron su legado con nuevas traducciones y ediciones. Efectivamente, su notoriedad se formaliza con la traducción de Smollett y con la edición de Festivous Notes. En la recepción crítica de ambos trabajos se aprecia que las revistas literarias se hacían eco de las tendencias imperantes en torno a la obra cervantina que le imprimían una sensibilidad moderna a la percepción de su humor, alejándose de las interpretaciones cómico-burlescas del siglo anterior. De igual manera, la edición de Bowle se reconocía como una fuente enriquecedora para la comprensión de esta obra maestra. De este modo, estaba contribuyendo a encauzar los caminos del cervantismo inglés en los últimos años del siglo y favoreciendo el avance y la apertura de nuevos horizontes en torno a los estudios críticos de la obra de Cervantes en el curso del tiempo. 


\section{BIBLIOGRAFÍA CITADA}

Álvarez Calleja, María Antonia (2007). «La serie de traducciones de El Quijote y su influencia en el desarrollo de la literatura inglesa», en José Manuel Barrio Marco y María José Crespo Allué (eds.), La huella de Cervantes y del Quijote en la cultura anglosajona. Valladolid: Universidad, pp. 499-504.

Álvarez Faedo, María José (2007). «Lord Carteret y Cervantes: análisis del contexto sociohistórico que propició la primera iniciativa inglesa de editar el Quijote en español y ofrecer una biografía de su autor», en Emilio Martínez Mata (coord.), Cervantes y el Quijote: actas del coloquio internacional, Oviedo, 27-30 de octubre de 2004. Madrid: Arco Libros, pp. 227-238.

Amenedo Costa, Mónica (2017). «Miguel de Cervantes en The Monthly Review y The Critical Review: la prosa (1749-1800)», Archivum. LXVII, pp. 7-40.

Amenedo Costa, Mónica (2019). «Fuentes hemerográficas del siglo XVIII: recepción de Cervantes en obras teatrales y composiciones musicales británicas», Cuadernos de Estudios del Siglo XVIII. 29, pp. 305-320.

Baretti, Joseph (1770). A Journey from London to Genoa, through England, Portugal, Spain, and France. Londres: T. Davies.

Baretti, Joseph (1778). A Dictionary, Spanish and English, and English and Spanish. Londres: J. Nourse.

Carretero Muñoz, Rafael (2005). «Apuntes para una vindicación del Reverendo John Bowle, M. A., F.S.A., frente a los cargos vertidos contra él por Mr. Giuseppe Baretti», en Diego Martínez Torrón y Bernd Dietz (eds.), Cervantes y el ámbito anglosajón. Madrid: Sial, pp. 13-62.

Claris de Florian, Jean-Pierre (1783). Galatée, Roman Pastoral; Imité de Cervantes, par M. de Florian. París: Didot l'ainé.

Claris de Florian, Jean-Pierre (1785). [Vie de Cervantes]. The Life of Cervantes: Together with Remarks on his Writings. Translated from the French by William Walllbeck. Leeds: J. Bowling.

Colahan, Clark (2013). «Knight-Errantry. Code Word and Punch Line in Edmund Gayton's "Festivous Notes on Don Quixote" (1654 and 1768)», Parole Rubate. 8, pp. 159-169.

Cuevas Cervera, Francisco (2016). «Escribir la biografía de Cervantes como empresa dieciochesca: reescritura y proyección de la Vida de Cervantes de Juan Antonio Pellicer (1778-1797)», Cuadernos de estudios del siglo XVIII. 26, pp. 179-230.

Cunchillos Jaime, Carmelo (1987). «Traducciones inglesas del Quijote (1612-1800)», en Julio-César Santoyo e Isabel Verdaguer (coords.), De Clásicos y traducciones: versiones inglesas de clásicos españoles (s. XVI-XVII). Barcelona: PPU, pp. 89-114.

Cunchillos Jaime, Carmelo (1993). «La primera traducción inglesa del Quijote de Thomas Shelton: 1612-1620», Cuadernos de investigación filológica. 9 (1-2), pp. 63-90.

Davison, Philip (2012). «Don Quijote de Loyola: sus asociaciones por lectores a lo largo del tiempo», Cuadernos de Aleph. 4, pp. 47-74.

De Bruyn, Frans (2009). «The Critical Reception of Don Quixote in England, 1605-1900», en J. A. Garrido Ardila (ed.), The Cervantean Heritage: Reception and Influence of Cervantes in Britain. Oxford: Legenda, pp. 32-52.

Eisenberg, Daniel (2003). «La edición del Quijote de John Bowle (1781). Sus dos emisiones», Cervantes: Bulletin of the Cervantes Society of America. 23 (2), pp. 45-84.

Fitzmaurice-Kelly, James (1905). Cervantes in England. Oxford: Universidad.

Flores, Pedro, et al. (1604). Romancero general, en que se contienen todos los romances que andan impressos. Ahora nuevamente añadido, y enmendado. Madrid: Juan de la Cuesta. 
Forster, Antonia (1990). Index to Book Reviews in England 1749-1774. Carbondale: Southern Illinois University Press.

Garrido Ardila, J. A. (2005). «Traducción y recepción del Quijote en Gran Bretaña (1612-1774)», Anales Cervantinos. XXXVII, pp. 253-265. https://doi.org/10.3989/anacervantinos.2005.014.

Garrido Ardila, J. A. (2006). «Traducción y recepción del Quijote en los siglos XVII y XVIII», Bulletin of Hispanic Studies. 83 (5), pp. 32-45.

Garrido Ardila, J. A. (2009). «Thomas D’Urfey y la recepción del Quijote en el siglo XVII inglés», Hispanic Research Journal. 10 (2), pp. 91-107.

Gayton, Edmund (1768). Festivous Notes on the History and Adventures of the Renowned Don Quixote. Londres: Printed for F. Newbery.

Gerhard, Sandra Forbes (1982). Don Quixote and the Shelton Translation: A Stylistic Analysis. Madrid: José Porrúa Turanzas.

Graham, Walter (1930). English Literary Periodicals. Nueva York: Thomas Nelson and Sons.

Hayes, Julie Candler (2009). «Eighteenth-Century English Translations of Don Quixote», en J. A. Garrido Ardila (ed.), The Cervantean Heritage: Reception and Influence of Cervantes in Britain. Oxford: Legenda, pp. 66-75.

Luttikhuizen, Frances (1985). Las traducciones inglesas de las Novelas Ejemplares: traducciones y traductores 1640-1972. Barcelona: Universitat.

Martínez Mata, Emilio (2001). «El sentido oculto del Quijote: el origen de las interpretaciones trascendentes», en Antonio Bernat Vistarini (ed.), Volver a Cervantes. Actas del IV Congreso Internacional de la Asociación de Cervantistas, tomo II. Palma: Universitat de les Illes Balears, pp. 1201-1210.

Martínez Torrón, Diego (2005). «El Quijote de John Bowle», en Diego Martínez Torrón y Bernd Dietz (eds.), Cervantes y el ámbito anglosajón. Madrid: Sial, pp. 241-317.

Mayo, Arantza y J. A. Garrido Ardila (2009). «The English Translations of Cervantes's Works across the Centuries», en J. A. Garrido Ardila (ed.), The Cervantean Heritage: Reception and Influence of Cervantes in Britain. Oxford: Legenda, pp. 54-60.

Mühlschlegel, Ulrike (2011). «De paisajes y palabras: Joseph Baretti, viajero y lexicógrafo», en Ricarda Musser (ed.), El viaje y la percepción del otro: viajeros por la Península Ibérica y sus descripciones (siglos XVIII y XIX). Madrid: Iberoamericana, Frankfurt am Main, Vervuert, pp. 99-108.

Pardo García, Pedro Javier (2007). «El Siglo de Oro del Quijote en la literatura inglesa, 17401840», en José Manuel Barrio Marco y María José Crespo Allué (eds.), La huella de Cervantes y del Quijote en la cultura anglosajona. Valladolid: Universidad, pp. 133-158.

Rey Hazas, Antonio y Juan Ramón Muñoz Sánchez (2006). El nacimiento del cervantismo: Cervantes y el Quijote en el siglo XVIII. Madrid: Verbum.

Roper, Derek (1978). Reviewing before the Edinburgh 1788-1802. Londres: Methuen \& Co.

Rutherford, John (2007) «Brevísima historia de las traducciones inglesas de Don Quijote», en José Manuel Barrio Marco y María José Crespo Allué (eds.), La huella de Cervantes y del Quijote en la cultura anglosajona. Valladolid: Universidad, pp. 481-498.

Sabik, Kazimierz (1990). «La recepción de la obra de Cervantes en Polonia en el periodo de la Ilustración y el Romanticismo (1781-1855)», Actas del II Coloquio Internacional de la Asociación de Cervantistas. Barcelona: Anthropos, pp. 307-318.

Valdés Rodríguez, Cristina (2007). «La imagen de don Quijote en las traducciones inglesas del siglo XVIII», en Emilio Martínez Mata (coord.), Cervantes y el Quijote: actas del coloquio internacional. Madrid: Arco Libros, pp. 239-248. 